\title{
Epidural fentanyl plus bupivacaine 0.125 per cent for labour: analgesic effects
}

\begin{abstract}
Ninety-five healthy nulliparous women, ASA physical status -II with an uncomplicated pregnancy and single fetus in vertex position were given lumbar epidural analgesia. Patients in Group $A(n=35)$ received bupivacaine 0.125 per cent with epinephrine 1:800,000; Groups $B(n=30)$ and $C(n=30)$ received the same agents as Group $A$ but with the addition to the initial dose of 50 or $100 \mu \mathrm{g}$ of fentanyl respectively. All patienis were evaluated for duration and quality of analgesia, duration of labour, method of delivery and toral dose of bupivacaine used. The addition of either 50 or $100 \mu \mathrm{g}$ of fentanyl resulted in ionger duration of analgesia $193 \pm 9 \mathrm{~min}$ and $106 \pm 8 \mathrm{~min}$ respectively vs $55 \pm 7$ ) and reduced bupivacaine tota! doses ( 64 \pm 0.03 and $55 \pm 1.5$ respectively $15109.5 \pm 1.3$ ). Only the addition of $100 \mathrm{\mu g}$ of fentanyl improved significantly the quality of analgesia $(43.3$ per cent of excellent scores vs 6.6 per cent in Group $B$ and 5.7 per cent in Group A). Addition of fertonyl dicd not affect the duration of labour, the methad of delivery and the neonatal neurobehaviour scores.
\end{abstract}

The combination of epidural local anaesthetics and fentanyl has been demonstrated to have benefit in anaesthesia for labour and delivery. ${ }^{1,2}$ Because fentanyl has no effects on sympathetic or motor neurons, ${ }^{3}$ it provides certain advantages over local anaesthetics, but has been shown to be inadequate as the sole agent. ${ }^{4}$

Bupivacaine 0.125 per cent has been reported to produce satisfactory analgesia for labour. ${ }^{5}$ There is evidence that diluted solutions of local anaesthetics in a larger volume are more effective than concentrated solutions in a small volume. ${ }^{6}$ Moreover diluted concen-

\section{Key words}

ANAESTHESIA: Obstetric; ANAESTHESIA: regional, epidural; ANALGESICS, NARCOTIC: fentanyl.

From the Department of Anaesthesia, Ospedale Fatebenefratelli, Isola Tiberina, Rome, Italy.

Address correspondence 1o: Dr. Giorgio Capogna, $\vee$. Maria Saveria Sanzi, 21, 00151 Roma, Italy. trations of bupivacaine, having less motor effects, may be useful in reducing operative deliveries. ${ }^{7}$

On the other hand, when low concentations of local anaesthetics are used alone, analgesia may be incomplete, especially in the second stage of labour. ${ }^{8}$ Indeed, limited dosages of diluted local anaesthetics are sufficient to block the non-myelinated $\mathrm{C}$-fibres in the first stage of labour, but may be inadequate to block the myelinated A-delta fibres in the second stage. ${ }^{8}$ The combination of bupivacaine with fentanyl has been shown to result in longer and more effective analgesia. ${ }^{3,8}$ However, the studies performed to date have not documented the effect of varying the dosage of fentanyl added to 0.125 per cent bupivacaine as the sole local anaesthetic throughout labour.

The present double-blind study was designed to evaluate if the addition of fentanyl in two different doses to 0.125 per cent bupivacaine affects the duration and the quality of analgesia, the length of labour and the total dose of bupivacaine required.

\section{Methods}

Informed consent was obtained from each patient and the study was approved by the Hospital Human Investigation Committee. Ninety-five healthy nulliparous labouring women, each with an uncomplicated pregnancy and a single fetus in the vertex position, were assigned randomly to one of the following groups: Group $A(n=35)$ received epidural bupivacaine 0.125 per cent with epinephrine 1:800,000; Group B $(n=30)$ and Group C ( $n=$ 30) received bupivacaine 0.125 per cent with epinephrine $1: 800,000$ with the addition of $50 \mathrm{or} 100 \mu \mathrm{g}$ of fentany] respectively, to a total volume, in all three groups, of 12 $\mathrm{ml}$.

When cervical dilatation had reached $4 \mathrm{~cm}$, and after the infusion of $500 \mathrm{ml}$ of lactated Ringer's solution, the epidural block was established. The procedure was performed using a 16G Tuohy needle, with the parturient in left lateral decubitus position. A catheter was piaced at $\mathrm{L}_{2}-\mathrm{L}_{3}$ interspace, using a loss of resistance technique and advancing the catheter $2 \mathrm{~cm}$ cephalad.

The patients were then placed in the supine position, 
with left uterine displacement, and the solution was injected through the catheter, according to the randomization protocol.

After the initial dose, additional doses of $12 \mathrm{ml}$ of bupivacaine 0.125 per cent with epinephrine 1:800,000 were injected when pain recurred, until the time of delivery. In the second stage of labour, the mother was placed in the semirecumbent position. All the patients received a dose of lidocaine one per cent for the episiotomy repair. The epidural catheter was not withdrawn until two hours after delivery, to allow for renewal of the block in the event that surgical treatment might be indicated

Baseline pain intensity, defined as the intensity of the pain assessed just prior to the block, has been measured with a $10 \mathrm{~cm}$ visual analogue painscale (visual analogue score). The quality of analgesia through the labour was assessed by the following scoring system:

EXCELLENT: when mother was completely painfree from the first or the second injection until the end of delivery. GOOD: when the mother was satisfied but some pain was experienced for a shor period during labour or delivery. INCOMPLETE: when the mother had significant pain relief, but experienced some pair during most of the time of labour and delivery.

FAILURE: when, after the start of epidural analgesia, pain was experienced during most time of labour and delivery. NOT POSSIBLE to Evaluate: delivery by Caesarean delivery.

The peak effect was defined as the first painless contraction. The duration of analgesia was assessed as the time of repeat injections. All patients were asked for the recurrence of pruritus. Evaluation of motor block was assessed with Bromage's criteria. ${ }^{9}$ Total dose of bupivacaine used, number of additional doses, duration and quality of analgesia, length of labour and mode of delivery were recorded.

Neonatal outcome was evaluated by Apgar scores, cord blood gas analysis and neurobehavioural testing, using the Neurologic and Adaptive Capacity Score (NACS) ${ }^{10}$ at the 2 nd and 24 th hour. Statistical analysis was performed by Kruskall-Wallis one-way analysis of variance, Student Newman-Keuls test and Chi-square test, when appropriate. A p value $<0.05$ was considered significant.

\section{Results}

The groups were similar with respect to age, weight and gestational age (Table I). Baseline pain intensity was six or more in all groups. There were no differences among the groups in the peak-effect of analgesia (13-18 min).

The analgesia was satisfactory in all groups. The addition of both doses of fentanyl reduced the incidence of incomplete analgesia (Group A 22.8 per cent; Group B 13.3 per cent; Group C 3.3 per cent). Moreover, the
TABLE I Population studied (Mean \pm SD)

\begin{tabular}{llll}
\hline Group & A & B & $C$ \\
\hline Maternal age (years) & $26.4 \pm 2.4$ & $25.1 \pm 2.7$ & $24.0 \pm 3.5$ \\
Matemal weight (kg) & $66.2 \pm 3.5$ & $65.3 \pm 2.5$ & $65.2 \pm 3.1$ \\
Gestat ional age (weeks) & $39.6 \pm 1.4$ & $38.0 \pm 1.7$ & $39.5 \pm 1.2$ \\
\hline
\end{tabular}

No significant differences between groups.

TABLE II Quality of analgesia

\begin{tabular}{lccc}
\hline Score (\%) & Group $A$ & Group $B$ & Group $C$ \\
\hline Excellent & 5.7 & 6.6 & $43.3^{*}$ \\
Good & 65.7 & 66.6 & 46.6 \\
Incomplete & 22.8 & $13.3 \dagger$ & $3.3 \ddagger$ \\
Failure & - & - & - \\
Not possible to evaluate & 5.7 & 10 & 6.6 \\
\hline
\end{tabular}

${ }^{*} p<0.001$ ys Groups A and B.

$\ddagger \mathrm{p}<0.05$ vs Group A.

$\$ p<0.001$ us Group A.

addition of $100 \mu \mathrm{g}$ of fentanyl to bupivacaine increased significantly the quality of analgesia $(P<0.001)$ (Table II). As shown in Table III, in Groups B and C mean duration of analgesia was significantly prolonged ( $\mathrm{p}<$ 0.001 ), number of supplementary doses was reduced ( $p<$ 0.01 ) and the mean total bupivacaine dose was decreased $(\mathrm{p}<0.001)$ as compared with Group $A$.

There were no differences among the groups in respect to mean lidocaine dose employed for the episiotomy repair (Table UI). No motor block was observed in any patients before the lidocaine dose.

There was no significant difference between groups in the mode of delivery, and the duration of labour was also comparable, as shown in Table IV. Itching was the only significant side effect in the fentanyl groups as compared with Group A, and was reported by six patients in Group $B$ and 16 patients in Group $C(p<0.0 I)$.

Itching was not a spontaneous complaint and was mostly confined to the area of analgesia.

TABLE 111 Effects of the addition of fentanyl on duration of analgesia, number of refill-doses and tosal bupivacaine dose. Dose of lidocaine used for episioromy repair (Mean \pm SD)

\begin{tabular}{lccc}
\hline & Group A & Group $B$ & Group 6 \\
\hline $\begin{array}{l}\text { Duration of analgesia } \\
\text { (min) }\end{array}$ & $55.0 \pm 7$ & $93.0 \pm 9^{*}$ & $106 \pm 8^{*}$ \\
$\begin{array}{l}\text { Number of refill-doses } \\
\text { Total bupivacaine dose } \\
\text { (mg) }\end{array}$ & $7.3 \pm 0.15$ & $4.3 \pm 0.02^{*}$ & $3.7 \pm 0.15^{*}$ \\
$\begin{array}{l}\text { Total lidocaine dose } \\
\text { (mg) }\end{array}$ & $109.5 \pm 1.3$ & $64 \pm 0.03 \dagger$ & $55 \pm 1.5 \dagger$ \\
\hline
\end{tabular}

*p $<0.01 ;$; $<0.001$ vs Group A 
TABLE IV Method of delivery (percentages)

\begin{tabular}{llll}
\hline$\%$ & Group A & Group B & Group C \\
\hline Spontaneous & 82.8 & 76.6 & 83.3 \\
Low forceps & 11.4 & 6.6 & 10 \\
Vacuum & - & 6.6 & - \\
Caesarean delivery & 5.7 & 10 & 6.6 \\
\hline
\end{tabular}

No significant differences between groups.

Neonatal outcome was good and was similar in all groups (Table V). No neonatal neurobehavioural score differences between groups were observed.

\section{Discussion}

The dose of bupivacaine employed in this study ( $15 \mathrm{mg}$ ) is well below the central nervous system or cardiac toxic threshold. ${ }^{11,12}$ The mean dose of bupivacaine injected was only $0.25 \mathrm{mg} \cdot \mathrm{kg}^{-1}$ every 55 minutes in the bupivacaine group, and every 106 minutes in the fentanylbupivacaine groups (mean values).

In contrast to this, IV infusions of $1.87 \mathrm{mg} \cdot \mathrm{kg}^{-1}$ over 60 minutes ${ }^{13}$ and $2 \mathrm{mg} \cdot \mathrm{kg}^{-1}$ over 150 minutes ${ }^{14}$ produced only subtoxic reactions. The low bupivacaine dose used represents a negligible risk in the event of accidental intravascular administration, with a further decreased risk with the addition of fentanyl, due to the lower mean dose of bupivacaine employed.

Decreased local anaesthetic requirements also lessen the danger of matemal hypotension. In addition, this low dose of bupivacaine may reduce the likelihood of a serious complication due to an inadvertent subarachnoid injection.

Maternal or neonatal respiratory depression subsequent to epidural narcoties remains a serious consideration. No delayed respiratory depression has been reported with the doses of fentanyl given within this study. ${ }^{15}$ Moreover, the

TABLE V Neonatal outcome

\begin{tabular}{|c|c|c|c|}
\hline & Group A & Group B & Growp $C$ \\
\hline \multicolumn{4}{|l|}{ Apgar score } \\
\hline lst $\min >7$ & $97.1 \%$ & $96.6 \%$ & $96.6 \%$ \\
\hline 5 th $\min >7$ & $100 \%$ & $96.6 \%$ & $100 \%$ \\
\hline \multicolumn{4}{|l|}{ Umbilical vein $\mathrm{pH}$} \\
\hline$($ mean \pm SD) & $7.32 \pm 0.07$ & $7.30 \pm 0.09$ & $7.31 \pm 0.05$ \\
\hline $\begin{array}{c}\text { Umbilical artery } \mathrm{pH} \\
\text { (mean } \pm \mathrm{SD})\end{array}$ & $7.17 \pm 0.04$ & $7.21 \pm 0.05$ & $7.22 \pm 0.07$ \\
\hline \multicolumn{4}{|l|}{ NACS score } \\
\hline 2nd hour $>35$ & $91.4 \%$ & $90 \%$ & $93.3 \%$ \\
\hline 24 th hour $>35$ & $100 \%$ & $96.6 \%$ & $100 \%$ \\
\hline $\begin{array}{c}\text { Infant weight (g) } \\
\text { (mean } \pm \text { SD) }\end{array}$ & $3204 \pm 96.3$ & $3196 \pm 143.2$ & $3213 \pm 90.2$ \\
\hline
\end{tabular}

No significant differences berween groups. addition of epinephrine slows vascular absorpion of epidural narcotics, ${ }^{16}$ reducing furthermore the risk of respiratory depression. Indeed maternal respiratory depression was not assessed in this study, but no neonatal effects were noted.

Profound analgesia may sometimes be thought by the patients to be unpleasant. By employing epidural anaesthesia with low concentrations of bupivacaine $(0.125$ per cent), our patients were able to preserve some perineal sensation, at least the feeling of pressure.

These advantages may be important with respect to reducing the incidence of use of forceps. With this technique the influence of instrumental delivery was minimal, despite the fact that all the patients were primiparae. This also could be due to the semirecumbent position of the patient in the second stage, that allowed a good perineal analgesia although with a low dose of bupivacaine. It has been shown that the position of the patient is important for the relief of perineal pain when low concentrations of local anaesthetics are used. ${ }^{17}$

In this study, the addition of $100 \mu \mathrm{g}$ of fentanyl increased significantly the quality of analgesia, preserving the benefit of a low dose of local anaesthetic. Previously $80-100 \mu \mathrm{g}$ of fentanyl was demonstrated to be effective in producing good perineal analgesia in the presence of a persistant occipito-posterior position. ${ }^{3,18}$ The addition of either 50 or $100 \mu \mathrm{g}$ of fentanyl to the bupivacaine resulted in a more prolonged duration of analgesia, with a reduced number of additional doses through the labour and of the total dose of bupivacaine employed. A shorter first stage of labour has been reported with the addition of 50 or $100 \mu \mathrm{g}$ of fentanyl to 0.25 per cent bupivacaine: ${ }^{19}$ this finding was not observed in our study.

The addition of fentanyl did not affect the peak-effect of analgesia, the duration of labour, the mode of delivery or the neonatal outcome, when compared with the 0.125 per cent bupivacaine group.

The prolonged analgesia obtained with the addition of fentanyl is in accordance with the fentanyl clearance from the cerebrospinal fluid, and with the mean duration of fentanyl analgesia of four to five hours. ${ }^{20}$

Finally, the main advantage of the addition of $100 \mu \mathrm{g}$ of fentanyl to 0.125 per cent bupivacaine is to increase the quality of analgesia, including at the same time the increase of safety for the mother, without affecting the newbom.

\section{References}

1 Youngstrom $P$, Eastwood D, Patei $H$, Bhatia $R$, Cowan $R$, Sutheimeer $C$. Epidural fentanyl and bupivacaine in labor: double blind study. Anesthesiology 1984; 61: A414. 
2 Desprats $R$, Mandry J, Granjean H, Amar B, Pontonnier $G$, Lareng $L$. Analgésie peridurale au cours du travail: étude comparative de l'association. fentanyl-marcaine et de la marcaine seule. J Gyn Obstet Biol Repr 1983; 12: 901-5.

3 Justins DM, Francis D, Houlton PG, Reynolds F. A controlled trial of extradural fentanyl in labour. $\mathrm{Br} \mathrm{J}$ Anaesth 1982; 54: 409-14.

4 Carrie IES, O'Sullivan GM,Leegabin R. Epidural fentanyl in labour. Anaesthesia 1981; 36: 965-9.

5 Bleyaert A, Soetens $M$, Vaes $L$, Van Steenberge $A$, Van der Dorck A. Bupivacaine $0.125 \%$ in obstetric epidural analgesia: experience in three thousand cases. Anesthesiology $1979 ; 51: 435-8$.

6 Knepp NB, Cheer TG, Gutshe BB. Bupivacaine: continuous infusion epidural analgesia for labor. Anesthesiology 1983; 59: A407.

7 Van Zundert A, Vanderaa PP, Van der Donck A, Meeuwis $H$, Vaes $L$. Motor blockade expulsion times and instrumental deliveries associated with epidural analgesia for vaginal delivery. Obstet Anesth Digest 1984; 4: 152-6.

8 Gauthier et Lafayer. Precis d'anesthesie loco-regionale. Masson (Ed.) Paris, 1985.

9 Bromage PR. Epidural analgesia. Philadelphia: WB Saunders, 1978 p. 144.

10 Amiel-Tison $C$, Barrier $G$, Shnider $M$, Levinson $G$, Huges $S$, Stefani, $S$. A new neurologic and adaptive capacity scoring system for evaluating obstetric medications in fullterm newborns. Anesthesiology 1982; 56: 340-50.

11 Reynolds $F$. A comparison of the potential toxicity of bupivacaine, lidocaine and mepivacaine during epidural blockade for surgery. Br J Anaesth 1971; 43: 567-70.

12 Wiklund L, Berlin-Wahlen A, Splanchnic elimination and systemic toxicity of bupivacaine and etidocaine in man Acta Anaesthesiol Scand 1977; 21:521-8.

13 Morishima $H O$, Pedersen $H$, Finster $M$ et al. Bupivacaine toxicity in pregnant and nompregnant ewcs. Ancsthcsiology $1985 ; 63 ; 134-9$.

14 Liu P, Feldman HS, Giasi R, Fatterson MK, Covino BG Comparative CNS toxicity of lidocaine, etidocaine, bupivacaine and tetracaine in awake dogs following rapid IV administration. Anesth Analg 1983; 62: 375-9.

15 Lam AM, Knill RL,Thompson JL, Clement GP, Varkey GP. Spoel WE. Epidural fentanyl does not cause delayed respiratory depression. Can Anaesth Soc J 1983; 30: S789.

16 Bromage PR, Camporesi EM, Durant PAC, Nielsen CH Influence of epinephrine as an adjuvant to epidural morphine. Anesthesiology 1983; 58: 257-62.

17 Hanson $A L$, Hanson $B$. Continuous mini-infusion of bupivacaine into the epidural space during labor. Regional Anesth 1985; 10: 139-44.
18 Baraka A, Maktaby $M$, Noueihid $R$. Epidural meperidinebupivacaine for obstetric analgesia. Anesth Analg 1982; 61: 652-6.

19 Cohen SE, Tan S, Albright GA, Halpern J. Epidural fentanyl/bupivacaine combinations for labor analgesia: effect of varing dosages. Anesthesiology 1986; 65: A368

20 Muller $H$, Borner $U$, Stoianov $M$, Hempelmen $G$. The perioperative use of epicural opiate. In: Yaksh $\mathrm{TL}$, Muller H, Henquist A. Ancsthesiology and Intensive Care Medicine: Spinal opiate analgesia. Heidelberg,Springer Verlag, 1982; p. 67.

\section{Résumé}

Quatre-vingl-quinze femmes nullipares en bonne santé ASA classe I-II lors d'une grossesse non-compliquée ont reçu une analgésie épidurale tombaire. Les parientes du groupe $A(\boldsymbol{n}=$ 35) ont reçu de la bupivacaine 0.125 pour cent avec épinéphrine $1: 800,000:$ les patientes du groupe $B(n=30)$ et $C(n=30)$ ont reçu les mêmes médicaments que celles du groupe $A$ mais avec l'addition d'une dose initiale de 50 ou $100 \mu \mathrm{g}$ de fentanyl respectivement. Les pasientes furent évaluées pour la durée et la qualité de l"analgésie, la durée du travail, la méthode d'accouchement et la dose totale de bupivacaïne utilisée. L'addition de 50 et $100 \mu \mathrm{g}$ de fentanyl a prolongé la durée de l'analgésie $193 \pm 9$ minutes et $106 \pm 8$ minutes respectivement versus $55 \pm 7$ ) et a réduit les doses totales de bupivacaine $(64 \pm 0.003$ et $55 \pm 1.5$ respectivement versus $109.5 \pm 1.3$ ). Seule l'addition de $100 \mathrm{\mu g}$ de fentanyl a amélioré significativement la qualité de l' analgésié (43.3 pour cent des scores excellents versus 6.6 pour cent dans le groupe $B$ et 5.7 pour cent dans le groupe A). L'addition de fentanyl n'a pas affecté la durée du travail, et la méthode de l'accouchement el le score néonatal. 